\title{
ECONOMIA, SUJEITO E INSTITUIÇÃO SEGUNDO FOUCAULT ${ }^{1}$
}

Romildo Gomes Pinheiro (UCL) ${ }^{2}$

romildogp81@yahoo.com.br

Resumo: o artigo procura compreender o estatuto da crítica de Foucault do neoliberalismo a partir do conceito de biopolítica trabalhado no textos anteriores ao curso La naissance de labiopolitique. Dois pressupostos teóricos são mobilizados para compreender a passagem da problemática do biopoder àquela do neoliberalismo: Marx e o conceito de superpopulação relativa, pelo fato que a problemática de Foucault em torno do conceito de biopolítica gira em torno do conceito de população. Por outro lado, com Polanyi, nós podemos compreender de que maneira Foucault pensa a novidade do neoliberalismo contemporâneo no interior de uma analise das contradições do liberalismo enquanto capitalismo histórico. Em última instância, o artigo procura situar as categorias de análise do poder em Foucault no terreno da economia política.

Palavras-chave: biopolítica; neoliberalismo; Marx; capitalismo institucional.

\section{O SUJEITO PRODUTIVO ENTRE O INSTITUCIONAL E O ECONÔMICO}

Comecemos por uma proposição complexa de Foucault sobre Marx no curso Naissance de la biopolitique. Ela retoma um ponto de vista estratégico através do qual é possível compreendermos a relação problemática entre economia política e relações de poder ao longo dos cursos nos quais o

\footnotetext{
${ }^{1}$ Recebido: 16-01-2014/Aceito: 18-12-2015/Publicado on-line: 06-03-2016.

${ }^{2}$ Romildo Gomes Pinheiro é Pós-doutorando na Universidade Católica de Louvain e Pesquisador do Centre de Philosophie du Droit - Louvain la Neuve e Centre Europé, Louvain-la-Neuve, Bélgica.
} 
conceito de "governamentalidade" constitui o fio da meada do argumento de Foucault. Não se trata aqui de saber se o conceito de "governamentalidade" substitui o conceito de "biopolítica", ou o de "disciplina" nos trabalhos imediatamente anteriores do autor de Surveiller et punir. Mas de mostrar de que maneira a relação entre instituições de poder e economia retoma uma problemática central graças à qual nós podemos compreender, de um lado, a perspectiva que organiza a historicidade do capitalismo de "longa duração" na compreensão do liberalismo “clássico" e "contemporâneo", e, de outro lado, o problema da "contradição" entre Capital e Trabalho na sua relação com a política. A citação afirma que

ce que les économistes appellent 'capital', ce n'est en fait qu'un processu relevant d'une théorie purement économique, mais que ce processus n'a et ne peut avoir de réalité historique qu'à l'intérieur d'un capitalisme qui, lui, est économico-institutionnel, alors vous comprenez bien que le capitalisme historique que nous connaissons n'est pas déductible comme [étant] la seule figure possible et nécessaire de la logique du capital. En fait, on a historiquement un capitalisme, un capitalisme qui a sa singularité, mais qui, à travers cette singularité même, peut donner prise à un certain nombre de transformations institutionnelles et par conséquent économiques, un certain nombre de transformations économico-institutionnelles qui ouvrent devant lui un champ de possibilités. Dans le premier type d'analyse, référée entièrement à la logique du capital et de son accumulation, un seul capitalisme et par conséquence, bientôt, plus de capitalisme du tout. Dans l'autre possibilité, vous avez la singularité historique d'une figure économico-institutionnelle devant laquelle, par conséquence, s'ouvre, si du moins on se donne un peu de recul historique et un peu d'imagination économique, politique et institutionnelle, un champ de possibilités. C'est-à-dire que, dans cette bataille autour de l'histoire du capitalisme, de l'histoire du rôle de l'institution du droit, de la règle dans le capitalisme, on a là en fait tout un enjeu politique. (FOUCAULT 2004a, P. 169-171)

Foucault insiste essencialmente contra Marx que uma defi- 
nição do capitalismo unicamente do ponto de vista da acumulação de capitais é insuficiente para compreendermos sua singularidade histórica. Tudo se passa como se, sob esta perspectiva, a diferença específica do capitalismo enquanto sistema econômico dotado de uma estrutura e de um vir-a-ser próprio não fosse compreendido, uma vez que ele é reduzido a uma condição transhistórica de realização. Compreender a singularidade do capitalismo pressupõe, com efeito, que nós compreendamos em que medida uma moldura institucional torna possível sua sobrevivência, isto é, sua reprodução econômica. Uma dimensão estrutural, pois, deve ser introduzida no escopo de uma análise do capitalismo histórico, porque a assunção das leis econômicas de produção como uma segunda natureza supõe a existência de uma ordem que regula a dinâmica das trocas entre os agentes econômicos em uma economia-mundo. Todavia, cabe nos perguntarmos: esta dimensão institucional do capitalismo invalidaria, como parece supor Foucault, a compreensão dos processos de acumulação econômicos que lhe são subjacentes? De que maneira pensar a relação entre economia e governamentalidade à luz do conceito de capitalismo institucional?

Ao colocar em evidência a dimensão institucional como operador de normalização da reprodução das trocas mercantis - uma troca diferenciada na qual a economia põe o trabalho nos circuitos temporais da produção e nos espaços econômicos de reprodução, cujo "fetichismo" se exprime no preço dos produtos enquanto "norma" de atribuição de valor na operação de troca de mercadorias entre os agentes econômicos (capital e trabalho) -, Foucault insiste sobretudo sobre a relação entre as determinações normativas e institucionais dos processos econômicos. Mas cumpre investigar 
de que maneira as relações entre capitalismo e relações de poder permitem compreender este agenciamento entre $\mathrm{o}$ econômico e o institucional, nem tanto partindo de uma insistência teórica sobre o fato de que existe uma distinção entre os processos de acumulação e os fatores institucionais e jurídicos do capitalismo, isto é, normativos, como nota Foucault; mas de insistir sobre o significado desta articulação, e em que medida a reflexão de Foucault constitui um prolongamento da reflexão de Marx. De resto, a posição de Foucault sobre o "capitalismo institucional" como uma estrutura no interior da qual deve ser pensado o "capitalismo histórico", isto é, a historicidade dos processos econômicos no interior de uma determinada estrutura, se aproxima em larga medida dos autores ligados ao "capitalismo institucional", cuja perspectiva é justamente voltada a pensar a incrustação dos processos de acumulação nos mecanismos institucionais, como será retomado em seguida.

Uma perspectiva me parece evidente nesta equação entre o normativo e o econômico, se nós não partirmos da oposição entre processos de acumulação de capitais e a dimensão institucional, sistematicamente aludida por Foucault. Trata-se do conceito de população, isto é, da constituição do sujeito da produção social no interior de normas sociais. Sobre esta questão, retenhamos uma passagem do curso Sécurité, Territoire, Population na qual Foucault não se instala necessariamente na oposição aludida na citação acima. Trata-se de uma passagem na qual Foucault procura precisar a natureza da articulação entre a formação do domínio econômico, à medida que ele é irredutível ao caráter transhistórico da produção e da comercialização de riquezas, e a dimensão institucional, analisada por Foucault sob a ótica do conceito de "governamentalidade", por meio 
do conceito de população. Foucault atribui a indissociabilidade entre economia e instituição, isto é, o agenciamento de toda economia em instituições políticas e jurídicas, às "leis de população" do capitalismo moderno, cuja formulação essencial se encontra precisamente na crítica de tais leis desenvolvida no Capital.

Je crois que, pour résumer tout Ceci, on pourrait dire que si on cherche l'opérateur de transformation qui a fait passer de l'histoire naturelle à la biologie, de l'analyse des richesses à l'économie politique, de la grammaire générale à la philologie historique, l'opérateur qui a fait ainsi basculer tous ces systèmes, ces ensembles de savoirs vers les des langues, c'est à côté de la population qu'il faut le chercher. Non pas sous la forme qui consisterait à dire : les classes dirigeantes comprenant enfin l'importance de la population ont lancé dans cette direction les naturalistes, qui, du coup, se sont mués en biologistes, les grammairiens qui, du coup, se sont transformés en philologues et les financiers qui sont devenus économistes. Ce n'est pas sous cette forme-là, mais sous la forme suivante : c'est un jeu incessant entre les techniques de pouvoir et leur objet qui a petit à petit découpé dans le réel et comme champ de réalité la population et ses phénomènes spécifiques. Et c'est à partir de la constitution de la population comme corrélatif des techniques de pouvoir que l'on a pu voir s'ouvrir toute une série de domaines d'objets pour des savoirs possibles. Et en retour, c'est parce que ces savoirs découpaient sans cesse de nouveaux objets que la population a pu se constituer, se continuer, se maintenir comme corrélatif privilégié des mécanismes modernes de pouvoir. ( FOUCAULT 2004b, P. 81)

Esta passagem procura compreender a determinação do domínio econômico como uma "segunda natureza" pela constituição das populações por formas de poder, correlativamente à interrogação sobre o surgimento da economia política enquanto pretensão científica voltada a determinar a natureza deste domínio ${ }^{3}$. Como é sabido pela leitura do

\footnotetext{
${ }^{3}$ Cf. G. Lucaks em Histoire et conscience de classe, trad. K. Alexos e J. Bois, Paris, Ed. Minuit, 1969, p. 134.
} 
Prefácio à critica da economia política, as populações constituem o sujeito da produção social (MARX 2014, P. 48). Mas se trata de um Sujeito cindido sob o duplo aspecto da produção de valor de uso e da produção de valor de troca, ao mesmo tempo sujeito concreto e sujeito abstrato. Foucault retoma a compreensão de Marx sobre as populações como um duplo "empirico-transcendental" através do qual é possível investigar a especificidade da economia moderna, tanto enquanto realidade econômica, tanto quanto um saber científico cujas condições de possibilidade não são imediatamente dadas na aparência econômica. Investigar a economia sob este duplo aspecto significa problematizar o "sujeito produtivo" correlativo às leis da economia, isto é, de que maneira os desejos das populações são convertidos em um sujeito abstrato constituído por leis econômicas homo economicus.

Quando esta determinação se torna fundamental, o equilíbrio vital da população passa a canalizar a emergência de problemas irredutíveis ao comércio e ao domínio jurídico enquanto representação de um povo constituído em uma unidade política. Pensar então a problemática relativa ao "biopoder" significa retomar uma discussão sobre o problema da socialização da vida com a emergência das populações como um sujeito social e político na nova cena da história: de que maneira regulamentar a relação das massas populacionais com seu território? Quais são as formas de sofrimento humano que afligem uma população, assim que as novas formas de saber que afetam as regularidades dos fluxos populacionais, etc.? Segundo Foucault, para dar conta deste conjunto de problemas associados à emergência dos desorganizados na economia, são necessárias normas sociais de regulação capazes de transformar este sujeito em- 
pírico em um sujeito abstrato, capaz assim de engrenar a produção econômica; porque não se trata mais de considerá-lo como um fenômeno natural irredutível à sociabilidade dos homens, isto é, às trocas econômicas entre os agentes no interior de normas sociais; nem tampouco à uma unidade política apreensível por um ordenamento jurídico. Foucault retoma em várias passagens de seus textos esta questão: a liberação das populações excedentárias na civilização material do século XVIII, após a decolagem ao mesmo tempo demográfica, econômica e social da Europa (FOUCAULT 2001, P. 17), colocava o imperativo do controle social e político das populações para que a expansão das sociedades capitalistas fosse assegurada (sécurisée) em função das normas da produção moderna. A norma da produção moderna que regula o trabalho em função do tempo socialmente necessário à produção defronta-se diante de um trabalho vivo irredutível a uma simples operação mecânica de racionalização, sobre o qual é necessário, contudo, imprimir uma normalização social. (CANGUILHEM 1947, P. 04).

Nos seus comentários seguidos à citação acima, Foucault faz referência justamente à ruptura epistemológica entre Marx e Malthus à propósito das leis de população para explicar a especificidade da economia moderna. Esta oposição é compreendida pela diferença entre a apreensão "bio-econômica" do conceito de população por Malthus, e a crítica desta perspectiva por uma investigação sobre o registro histórico-político da idéia de classe. Certo, pensar a articulação entre política e economia graças à constituição política das populações sob a ótica do conceito de classe, significa tomar as populações não simplesmente como um objeto de medidas administrativas de um governo econô- 
mico, mas como um sujeito coletivo, formado por grupos que configuram novas formas de coletividade e que inauguram novas formas de ação comum vis-à-vis do "processo de valorização econômica” pelo tempo de trabalho social investido. Mas para Foucault, trata-se de se instalar na fronteira mesma entre Malthus e Marx, como se finalmente a economia estivesse embedness no interior da divisão entre um proletariado industrial e um exército industrial de reserva, tratando-se, pois, de examinar esta zona heterônoma através da qual o capitalismo se expande enquanto economiamundo, substituindo a Contradição entre as classes pela Administração de um surplus excedentário reflexivamente produzido no interior do sistema, como se o deslocamento da fronteira que opõe capital e trabalho vivo somente fosse possível por meio de um "trabalho morto" levado a cabo pelos desorganizados da economia. Trata-se, com efeito, de compreender de que maneira a "economia" se instaura pelo vínculo com o "trabalho", e de que maneira a questão "institucional" do capitalismo é determinante na equação da relação entre economia e homo economicus.

Sobre esta questão, os capítulos XXIII-XXIV do Capital são incontornáveis. A perspectiva ali adotada por Marx é a de explicar o modo pelo qual a economia capitalista se remete ao Estado pelo laço que une acumulação de capitais e crescimento populacional. Tal abordagem serve a Marx como um pressuposto explicativo concernente à disjunção entre população e lute de classes aludidas por Foucault. Marx demonstra de que maneira o funcionamento da economia capitalista opera pela produção da superfluidade do trabalho à medida que se operam transformações na base que compõe a relação entre o capital constante e os elementos variáveis da produção, isto é, a força de trabalho. Com 
efeito, com o acúmulo de capitais e a conseqüente diminuição correlativa de seus componentes variáveis relativamente a seus elementos constantes, produz-se uma população trabalhadora excedentária cuja relatividade é medida pela sua superfluidade vis-à-vis dos objetivos da acumulação capitalista. A acumulação de capitais transforma o lucro auferido com a exploração do trabalho não-pago em incremento do capital inicial cujo crescimento é irrigado por uma força de trabalho explorável no mundo da produção. De um lado, esta composição entre acumulação de capital e a exigência de uma força de trabalho, significa que o modo de produção capitalista exige como condição sine qua non para sua reprodução o controle de uma população que deve ser convertida e constituída em força de trabalho. Mas por outro lado, a quantidade de força de trabalho constituída em força produtiva não é suficiente para determinar o modo de reprodução do sistema. É necessário uma "arma industrial de reserva" para que a organização entre a oferta e a demanda de trabalho opere nos limites da exploração capitalista. Com efeito, uma população relativa exerce uma pressão sobre a população economicamente ativa em momentos de estagnação econômica ou de prosperidade média, minando a capacidade de resistência do Trabalho em períodos de crise da produção. "O capital age de dois lados ao mesmo tempo. Quando a acumulação multiplica de um lado a demanda de trabalho, ela multiplica de outro a oferta de trabalhadores, liberando estes, mas por outro lado, a pressão dos inocupados constrange ao mesmo tempo os ocupados a mobilizar mais trabalho, e em certa medida, torna a oferta de trabalho independente da oferta de trabalhadores." (MARX 2009, P. 718) Em outras palavras, se o Capital no seu processo de acumulação sem fim 
não pode saciar sua sede de lucro sem a incorporação do trabalho nas engrenagens da produção, a questão que permanece é de que modo a contradição entre a demanda de trabalho e a existência de uma população excedentária é regulada no interior da reprodução do sistema de acumulação para que o trabalho vivo não possa se insurgir. De um lado, trata-se de uma operação de conversão das populações excedentárias nas engrenagens da exploração do trabalho pela desapropriação da terra, pelos enclousures, etc, cujo objetivo é a constituição de uma forca de trabalho abstrata. Mas de outro lado, trata-se de enquadrar as populações excedentárias como forma de produzir uma heteronomia (Etienne Balibar) política entre o Trabalho e o Capital pela administração da existência de uma população industrial de reserva.

Retenhamos então duas passagens de Foucault do curso Naissance de la biopolitique, ilustrativas deste teorema através do qual estamos procurando desvendar os contornos da posição de Foucault relativamente ao problema concernente à relação entre economia e população, e qual o lugar da idéia de "governamentalidade" no interior desta relação.

$\mathrm{Na}$ primeira passagem que nos interessa sublinhar, Foucault discute o travamento da contradição entre trabatho e capital quando ele observa os efeitos de neutralização das políticas sociais de "segurança" (sécurité) propostas em matéria de política social nos anos 70 pela indexação neoliberal da economia. Foucault utiliza os mesmos esquemas de análise oriundos da sua problemática sobre o "biopoder", o que evidencia bem a pertinência do conceito de população relativa em seus esquemas teóricos em torno da questão do "poder". Surgidas após as políticas de Estado de bem-estar social, as políticas neoliberais de sécurité social são voltadas 
para a promoção de subvenções sociais aos indivíduos que teriam descido aquém do limiar de sobrevivência social. Tais políticas tinham por objetivo atacar «os efeitos da pobreza» (FOUCAULT 2004a, P. 210) sem permitir uma ingerência na governamentalidade liberal da economia, isto é, na idéia de que os processos econômicos são regulados por uma correta administração das coisas. A questão social é assim acordada ao fato de que os pobres que ultrapassaram o limiar da sobrevivência social em uma economia de mercado não mais centrada sob o pleno emprego, devem ser subvencionados com o propósito de serem eventualmente utilizados enquanto forca de trabalho produtiva. Citemos essa passagem de Foucault:

Mais ça implique un fonds de populations flottantes, un fonds de populations liminaires, infra- ou supraliminaires, dans lequel des mécanismes d'assurance permettront à chacun de subsister, de subsister d'une certaine façon, de subsister de telle manière qu'il pourra toujours être candidat à un emploi possible, si les conditions du marché l'exigent. C'est un tout autre système que celui par lequel le capitalisme du XVIIIème ou du XIXème siècle s'est constitué et s'est développé, lorsqu'il avait affaire à une population paysanne qui pouvait constituer un perpétuel réservoir de main-d'œuvre. Dès lors que l'économie fonctionne comme elle fonctionne maintenant, dès lors que la population paysanne ne peut plus assurer cette espèce de fonds perpétuel de main-d'œuvre, il faut la constituer sur tout un autre mode.(FOUCAULT 2004a, P. 212-213)

Do ponto de vista da gestão biopolítica das populações no interior do processo de acumulação, a proteção social das populações excedentárias por mecanismos de assistência social implica a gestão de um estoque populacional em conformidade com a reprodução do sistema pela extração de um excesso de trabalho nas engrenagens da acumulação. Foucault afirma sobre esta questão que 
On va avoir une population qui va être, du côté du plancher économique, une population en perpétuelle mobilité entre une assistance qui sera accordée si un certain nombre d'aléas se produisent et si on descend au-dessous du seuil, et qui sera, au contraire, à la fois utilisée et utilisable si les besoins économiques le nécessitent, si les possibilités économiques en offrent l'occasion. Ce sera donc une espèce de population flottante infra- et supraliminaire, population liminaire qui constituera, pour une économie qui justement a renoncé à l'objectif du plein emploi, une perpétuelle réserve de main-d'œuvre dans laquelle on pourra puiser si besoin est, mais que l'on pourra renvoyer à son statut d'assistée si besoin est également. (FOUCAULT 2004a, P. 212)

Trata-se de constituir subjetivamente o trabalho vivo enquanto arma industrial de reserva, de modo que haja uma 'neutralização' da contradição entre a exploração da força de trabalho e os imperativos da acumulação. Sobre esta questão, a descrição de Robert Castel sobre as populações supranumerárias em Les métamorphoses de la question sociale comporta uma incidência descritiva interessante concernente ao relevo histórico da descrição de Foucault. Porque Castel procura, tal como Foucault, inscrever as regulações sobre as populações relativamente aos aparelhos produtivos através da perenidade das relações de dominação que articulam aparelhos produtivos e reprodução populacional. Para Castel, a relação entre a emergência das populações supranumerárias e a instituição do salariado moderno deve ser compreendida sob esta ótica. Ao contrário do que supõe Foucault quando ele menciona a idéia de uma "otimização" entre crescimento populacional e capitalismo industrial, Castel explica que as populações objeto de formas de regulação política do capitalismo moderno são marcadas por uma situação paradoxal na qual o fim das regulações suscitadas em função da generalização de epidemias, são marcadas por situação de vulnerabilidade de massa, decorren- 
te do crescimento demográfico que tornou os assalariados mais pobres e mais dependentes dos riscos em função da livre disposição capitalista do trabalho em um mercado concorrencial. Segundo Castel, a imposição do paradigma do livre acesso ao trabalho gerou uma população relativa no quadro de uma vulnerabilidade de massa, característico das populações excedentárias que viviam uma situação de indigência, isto é, pela ausência de recursos para assegurar sua sobrevivência. Castel demonstra que ao lado desta indigência estrutural, estas populações eram marcadas por uma precariedade social em que situações conjunturais poderiam impulsionar populações inteiras a passarem "além do limiar dos recursos que permitem uma autonomia mínima”. (CASTEL 1995, P. 62) Por conseguinte, a melhora da saúde das populações decorrentes da liberação da vida de entraves estruturais descrita por Foucault foi paradoxalmente possível sob a condição da vulnerabilidade social manifesta pelo desenraizamento e a condição de «dependência natural» como um fato massivo das sociedades européias no século XVIII. É o que Castel chama de «o deslizamento que traduz a montagem paradoxal da melhora/piora da vida das pessoas simples no fim do Antigo regime».(CASTEL 1995, P. 272)

A tese de Castel é que as populações excedentárias são marcadas por uma precariedade geradora de uma vulnerabilidade de massa onde os suportes relacionais entram em colapso. A caracterização desta situação como uma vulnerabilidade de massa demonstra que a condição social destas populações pertence não à periferia do sistema político, situação típica de certos grupos sociais que são excluídos socialmente, mas à interioridade do sistema social que recria sua estrutura a partir de um limiar de exclusão 
característico de algumas figuras da precariedade. Esta condição de precariedade corresponde tanto à ordem do nãopertencimento comunitário dos que estão fora do circuitos sociais, como no exemplo paradigmático do vagabundo analisado por Castel a partir de Le Trosne, quanto à ordem da vulnerabilidade, isto é, a precariedade que condena e ameaça os grupos arrancados de suas próprias condições de existência. Em outras palavras, são as populações que «não tem nenhum lugar assinalado na estrutura social e no sistema de distribuição das posições socialmente reconhecidas, nem daquelas posições que fazem dos indigentes socorridos uma clientela reconhecida». (CASTEL 1995, P. 110)

Castel procura reatualizar a questão de Marx sobre o pauperismo por uma reflexão que retoma em vários aspectos a descrição de Foucault. Todavia, nós podemos nos interrogar em que medida ele permanece nos limites dos mecanismos de sécurité sociale sob o prisma da oposição entre proteção e ausência de trabalho, e não na perspectiva da constituição de uma supranumerarização do trabalho cujo resultado é minar a resistência à exploração do trabalho nos limites da reprodução do capitalismo. Cumpre então descrever de que maneira Foucault determina esta zona de heteronomia da política (Balibar) nas suas análises da "governamentalidade contemporânea".

\section{A COMPOSIÇÃO DO SUJEITO ABSTRATO NO INTERIOR DE UM CADRE}

Retenhamos criticamente a fórmula de Foucault utilizada a guisa de introdução. De um lado, ela nos adverte que uma lógica estritamente econômica não se instala necessariamente em uma dimensão uniforme e progressiva. Ao 
contrário, que um modelo institucional determina os contornos desta dinâmica expansiva do "capitalismo histórico". Marx no Capital reserva uma compreensão da articulação entre a reprodução econômica do capital, ocasionando uma demanda de um surplus de trabalho, e as instituições políticas do Estado, em particular pelo rule of Law consubstanciado em medidas jurídicas de exceção, quando ele analisa o capitalismo do ponto de vista de uma "acumulação original de capitais", isto é, este momento constitutivo da relação capitalista na qual uma relação de troca econômica é sobredeterminada pelos imperativos da força consubstanciados no rule of Law. Retomando as análises de Immanuel Wallerstein sobre a dimensão históricoinstitucional do capitalismo aludida por Foucault, o capitalismo histórico é definido pela acumulação de capitais no interior das coordenadas do tempo e do espaço, de maneira que a acumulação ilimitada constitui um modo de estruturação das trocas econômicas no interior de uma geografia na qual os agentes econômicos ocupam posições assimétricas. Partindo desta assimetria, os preços dos produtos são determinados pelo uso da força. Em outras palavras, o rule of Law se torna um mecanismo institucional essencial na determinação da equivalência das trocas econômicas entre diferentes regiões de uma economia-mundo. (WALLERSTEIN 1985, P. 28.) Segundo I. Wallerstein, a integração de novas zonas de comércio em uma economiamundo capitalista possui por objetivo contrabalançar os efeitos sobre a taxa de lucro decorrente de uma proletarização crescente, pela integração de novas forças de trabalho voltadas à semi-proletarização. (WALLERSTEIN 1985, P. 40) Na mesma veia institucionalista, Fernand Braudel coloca em evidência a distinção entre civilização material, 
mercado de trocas e capitalismo histórico, para dar conta do fato de que a dinâmica do capitalismo é irredutível a um mercado de trocas definido pelo equilíbrio concorrencial entre os agentes econômicos. Na realidade, o capitalismo histórico é um sistema social marcado pela extensão progressiva de relações comerciais além dos limites nacionais, seja pela manutenção do crédito, seja pela manipulação da moeda. Com efeito, trata-se de um sistema histórico marcado por uma lógica monopolística que organiza a acumulação sob uma ótica financeira de alto lucro que determina a vida material e a economia de mercado. Segundo Braudel, para que o sistema capitalista se expanda enquanto economiamundo, ele necessita de hierarquias sociais, isto é, de relações de poder que lhe preexistem, para que o preço dos produtos e da força de trabalho sejam ordenados no interior da totalidade capitalista.

Vista sob a ótica de Wallerstein e Braudel, a articulação entre economia e instituição no interior das "racionalidades governamentais foucauldianas", na qual se exprime tanto um lógica de racionalização interna por meio da economia política, quanto um modo externo de universalização de um mercado universal em uma economia-mundo, não parece assim em contradição com a perspectiva que ele mesmo evoca a respeito da historicidade de um capitalismo de longa duração. Retomando em particular a questão de Wallerstein, o conceito de quadro (cadre) discutido na lição de 14 de fevereiro de 1979 do curso Naissance de la biopolitique faz precisamente referência a esta imbricação entre economia e instituição pela discussão do ménage da força de trabalho.

Questão crucial, se atinarmos para o fato que a codeterminação entre o econômico e o não-econômico é pos- 
sível pelo conceito de população, segundo a passagem já citada do curso Securité, Territoire, Population que nos serviu de ponto de partida para descortinarmos o texto de Foucault. $\mathrm{Na}$ lição de 14 de fevereiro de 1979, Foucault retoma a problemática de Eucken sobre as possibilidades de integração da agricultura européia em uma economia de mercado que necessita de novas fronteiras. Para que isso seja possível, segundo Eucken, é necessário intervir sobre elementos que não são diretamente econômicos, mas que são elementos condicionantes para uma economia de mercado que necessita de expansão. É justamente este conjunto de elementos no interior dos quais as populações agrícolas são condicionadas que Eucken chama de quadro (cadre). Definir um "quadro" significa atinar para os elementos no interior dos quais se inscreve uma população enquanto sujeito da produção agrícola, passando por técnicas agrícolas, nível de formação e de aprendizagem das populações, política migratória e instrumentos de produção, regimes jurídicos de exploração do solo, assim que do nível do clima e da alocação do solo. Observar a conversão de uma população agrícola no interior de um "quadro" significa atinar para com elementos não econômicos que entram no modo de constituição do sujeito produtivo da economia. É o que Foucault evoca pelo título de intervenções ordenadoras (interventions ordonnatrices) que determinam o meio natural ( milieu) no qual uma determinada população se inscreve.

Na lição de 14 de março de 1979 do curso Naissance de la biopolitique, Foucault prolonga esta discussão do "quadro" pela discussão do ménage da força de trabalho pelas teorias do capital humano. Seguindo a perspectiva teórica segundo a qual a economia se encontra incrustada (embeddedness) em 
instituições não-econômicas pela determinação das populações como sujeito da produção, Foucault retoma tais teorias porque elas tratam essencialmente de arregimentar à exterioridade do trabalho em vista da formação do "trabalho abstrato" pela integração de novas dimensões exteriores aos processos econômicos. Deste ponto de vista, a reflexão sobre a conversão das populações na composição de um "quadro" (FOUCAULT 2004a, P. 145-146) se orienta sob a ótica de uma reflexão sobre a relação entre capitalismo e subjetividade, trata-se de compreender as disposições dos agentes econômicos tomando-se em conta a formação do sujeito no interior de um quadro produtivo. Traduzindo em outros termos, para Foucault é preciso dar conta de uma problematização relativa às formas de subjetivação do trabalho no interior da "economia".

O manager define a forma com a qual a subjetividade do trabalho se desdobra no curso da realização de uma atividade produtiva no interior de um quadro produtivo. Para Gary Becker e Theodore W. Schultz, uma população de indivíduos é portadora de um capital pela integração do tempo individual e familial no interior da vida profissional dos indivíduos. Tudo se torna, com efeito, objeto de valorização econômica, de tal maneira que os mecanismos concorrenciais identificados por Foucault na perspectiva neoliberal se desdobram sobre a conduta e os hábitos dos sujeitos, desde que a normatividade do trabalho é apreendida pela operação de modelização do sujeito sobre si mesmo. Seguindo Foucault, a teoria econômica dos "neoliberais" pretende assim introduzir uma análise do trabalho enquanto atividade econômica tomando como referência o comportamento humano no trabalho no interior de um campo de análise. $O$ trabalho é deste modo um capital es- 
pecífico porque o salário do trabalho é definido como uma fonte de acumulação. A lógica entre acumulação capitalista como um fenômeno universal e a existência vital estando refletidas pela tomada de consideração da mobilização dos sujeitos nas empresas produtivas modernas. $\mathrm{Na}$ perspectiva da introdução do trabalho no campo da análise econômica, a questão do trabalho não consistirá mais na relação desta atividade no interior do sistema de produção por onde o capital se realiza enquanto valor a partir da exploração de um surplus de trabalho. A questão essencial consiste em analisar o trabalho como uma conduta econômica conduzida por um sujeito portador de liberdade no interior de um quadro produtivo, de maneira a que o travail vivant utilize os recursos que lhes são disponíveis com o objetivo de obter uma qualificação específica. Nesta perspectiva, o trabalho é compreendido como uma atividade racionalizável, e, portanto, como uma conduta econômica que deve ser enquadrada por uma intervenção política.

É por esta razão que Foucault retoma como conclusão da sua discussão sobre a relação entre "capital humano" e "capitalismo histórico" a relação crítica dos autores que formularam a idéia de "capital humano" com o pensamento de Schumpeter. Para Schumpeter, o desenvolvimento de novas competências laborais, isto é, o desenvolvimento da qualificação da força de trabalho como um vetor de inovação e progresso técnico constitui um meio de corrigir a queda progressiva da taxa de lucro, apontada por Rosa Luxemburgo, na esteira de Marx, como o motor da crise do capitalismo, corrigível, como se sabe, pela exportação de capital supérfluo e o acesso a novas fronteiras de conversão das populações em força de trabalho. (FOUCAULT 2004a, PP. 235-237) Na esteira de Marx e Luxemburgo, David 
Harvey, por exemplo, afirma que a teoria das crises do capitalismo é um elemento essencial para compreender a lógica do neoliberalismo, que segundo Harvey, deve ser inscrita no interior da história da acumulação econômica pela remoção das contínuas barreiras que se opõem à extensão da acumulação capitalista (HARVEY 2003). A sobrevivência do capitalismo histórico às crises de acumulação supõe o acesso a novas fronteiras econômicas, cujo resultado é tornar possível por meio de estruturas institucionais e geográficas a constituição de um nexo espacial e temporal às dinâmicas de acumulação capitalista. Relativamente às teorias sobre o capitalismo segundo as quais o rebaixamento da taxa de lucro característico das crises do capitalismo é decorrente das barreiras interpostas entre o processo de acumulação de capitais e o livre acesso à um estoque de força de trabalho disponível, Foucault mostra de que maneira a sobrevivência do capitalismo é exeqüível nos autores "neoliberais" pela constituição de uma nova relação econômica com o sujeito da produção. Tomando em conta a questão de Schumpeter sobre a sobrevida do capitalismo a partir do desenvolvimento de novas competências laborais, para os autores "neoliberais", os fenômenos de inovação tecnológica não são produzidos pela concorrência e pela atmosfera de estímulo à inovação que ela propícia; se as inovações tecnológicas são empreendidas, é porque elas são produtos de um capital humano aferível no nível da constituição subjetiva da força de trabalho, permitindo assim uma correção da baixa progressiva da taxa de lucro nas crises do capitalismo. 


\section{Foucault E A PONDERAC̣ÃO DE POLANYI}

Em uma espécie de curto-circuito histórico e conceitual com a armadura foucauldiana do liberalismo moderno e contemporâneo do curso Naissance de labiopolitique, o livro La Grande Transformation de Karl Polanyi menciona os autores ligados à corrente "ordo-liberal", como Von Mises et Walter Lippmann, para examinar o fato de que na formulação destes economistas paira uma ilusão quanto a uma determinação antropológica do sujeito pela satisfação das necessidades e a busca do lucro. Sem procurar uma distinção quanto à natureza do liberalismo clássico e do liberalismo contemporâneo, uma vez que este último não é propriamente o objeto do livro, Polanyi inscreve a diferença específica do mercado econômico moderno (marché économique) em um duplo movimento entre, de um lado, uma tendência de auto-regulação do livre mercado, consubstanciada pela imposição do preço dos produtos do mercado econômico como norma de indexação da vida social através da mercantilização da natureza, do homem e das relações sociais, e, de outro lado, um movimento de autodefesa da sociedade materializado por formas de proteções sociais relativamente à autonomização dos processos econômicos, manifestados pela contínua desapropriação do trabalho, da terra e da renda, assim que por formas de regulação institucionais impostas à tendência auto-reguladora do mercado ${ }^{4}$.

\footnotetext{
${ }^{4}$ Em um mercado intermediado pela moeda, a produção de mercadorias é comandada pelo preço que determina os lucros e a distribuição de mercadorias, uma vez que a aquisição de mercadorias no sistema de trocas é orientada pelo preço. Mais ainda: determinando a produção e a renda do trabalho em uma economia moderna, o preço que estabelece um equilíbrio na produção e distribuição, torna-se assim uma instituição social determinante pela condução do trabalho, da terra e da moeda em uma mesma lógica: o salário para a força de trabalho, a renda sobre a terra e o lucro sobre a utilização da moeda. Cf. K. Polanyi, La grande transformation, trad. C. Malamoud e M. Angeno, Gallimard, 1983.
} 
Os campos de possibilidade do capitalismo histórico aludidos por Foucault fazem referência ao fato que, para Polanyi, a institucionalização dos processos econômicos obedece a valores e motivações políticas, porque a economia humana é inscrita em instituições econômicas e nãoeconômicas. Tal qual a análise de Foucault sobre o liberalismo moderno e contemporâneo, Polanyi argumenta fundamentalmente que o livre mercado não possui nada de natural. Ao contrário, a crença no "deixar fazer" (laissez faire) é produto de um construtivismo jurídico-institucional que assegura as condições de possibilidade do mercado econômico. Para que o mercado funcione, é necessário uma forte intervenção do Estado por meio de um aparato governamental cuja função característica nos Estados modernos é a extração de impostos, a regulação da moeda, e o controle das fronteiras da força de trabalho. Um enorme intervencionismo contínuo, organizado e comandado por um forte aparelho estatal, é a prerrogativa de um Estado encarregado de regular o mercado, desde a existência de barreiras comerciais até a regulação do salário da força de trabalho. À dinâmica do 'biopoder' do mercado capitalista moderno que dispõe da vida dos sujeitos, se opõe a um movimento contra-factual de luta social marcado pela proteção da vida social relativamente à vulnerabilidade produzida pela extensão do mercado econômico.

No pensamento de Polanyi, esta contradição "biopolítica" observada no duplo movimento da economia entre a mercantilização generalizada e a proteção social, é acompanhada por uma compreensão substantiva da economia do ponto de vista do enraizamento do econômico em instituições não-econômicas. $\mathrm{O}$ autor do livro $\mathrm{A}$ Grande Transformação critica as teorias econômicas que partem do 
pressuposto da autonomia da economia com o objetivo de fundar seu objeto de estudo, sem interrogar a incrustação da economia nos domínios não econômicos de investigação. (POLANYI 2002,P.58-59). É nesta perspectiva que ele diferencia o mercado de trocas, exemplificado por ele pelo comércio do Don e do contra-Don, ou ainda pela gestão do comércio, de toda definição economicista do mercado como um sistema de auto-regulação.

Por outro lado, uma diferença essencial pode ser estabelecida entre os dois autores. Se Polanyi interroga o mercado contextualizando-o no interior dos sistemas sociais, isto é, demonstrando que este se torna um mercado econômico somente à medida que ele se autonomiza da determinação da sociedade, a contradição do liberalismo estando então inscrita neste duplo movimento de autonomização e reapropriação do mercado em relação à sociedade, a análise de Foucault opera em outro registro. Ao escrutar a razão neoliberal pelo eixo de um mercado concorrencial garantido pela intervenção do Estado, a perspectiva de Foucault amplia certos aspectos de uma descrição do neo-liberalismo que nos importa sublinhar para além da análise de Polanyi: a sobrevivência do capitalismo histórico, de um lado, por mecanismos de intervenção do Estado não mais fundado em trocas econômicas, mas na concorrência como norma de regulação das empresas na economia; de outro lado, pela produção normativa de um novo sujeito marcada pela imposição de normas concorrenciais em princípio de definição da identidade dos agentes econômicos. Para Foucault, se o capitalismo histórico sobreviveu às crises econômicas decorrentes do deslocamento das fronteiras entre economia e não-economia, tornando-se deste modo uma questão de atualidade histórica, é porque ele conjugou um 
modo de regulação política da sociedade sobre-determinado pela gestão das contradições sociais criadas pelas contradições do sistema econômico. E nesta perspectiva que no curso Naissance de la biopolitique o teorema do biopoder moderno segundo o qual a reprodução do capitalismo é assegurada por uma arma industrial de reserva que lhe faculta o acesso à uma força de trabalho que necessita ser constituída enquanto tal, é retraduzido por uma descrição de Foucault da sobre-vida do capitalismo tomando em conta a análise das crises do capitalismo segundo os autores ligados ao "ordo-neoliberalisme" ${ }^{5}$ Vejamos então como Foucault compreende o neo-liberalismo partindo dos autores justamente mencionados por Polanyi .

Os thinks-tanks reunidos no colóquio organizado por Walter Lippmann produziram uma versão americana e uma versão alemã do neoliberalismo, ambas examinadas por Foucault ao longo do curso. Para estas doutrinas, a sobrevivência da economia de mercado está ligada a mecanismos de intervenção incessante visando à regulação do mercado econômico, em oposição ao regime de governamentalidade do liberalismo clássico. "Un Etat sous surveillance de marché plutôt qu'un marché sous surveillance de l'Etat"

\footnotetext{
${ }^{5}$ Mas se é graças à compreensão do neoliberalismo como a última "grande transformação" que a análise de Foucault ganha toda sua força teórica, não inscreve Foucault a oposição entre neoliberalismo e nacional-socialismo no registro ideológico contemporâneo, ao invés de compreender o registro em que esta oposição se inscreve? Retomando à contrapelo uma teórica como Hannah Arendt, a significação do conceito de totalitarismo é reenviada aos "campos de trabalho" e de "extração de tributos" de "populações coloniais", empreendidos por uma Ideologia imperial de cunho universal, ao que ela não hesita de chamar uma acumulação primitiva de capitais produtora de uma arma industrial de reserva ou "população supérflua", cujos métodos fordistas de produção consistiam na "produção de cadáveres". Todavia, se Foucault analisa a relação entre Neoliberalismo e "Totalitarismo" tomando em conta o registro ideológico no interior do qual se inscreve os think tanks neoliberais, Arendt, como é sabido, permanece inscrita nos limites de uma oposição ideológica entre "Totalitarismo" e "Democracia Republicana", representada na época da Guerra Fria pela potência imperial americana.
} 
(FOUCAULT 2004a, P. 120), é a diferença fundamental entre o liberalismo clássico e o liberalismo contemporâneo, isto é, entre um liberalismo que retém do Estado um limite à racionalidade do mercado econômico, e um outro que toma em conta os mecanismos de intervenção do Estado na perspectiva da construção de um mercado que se formaliza pela concorrência entre os agentes econômicos. Ainda citando Foucault: «L'économie produit de la légitimité pour l'État qui en est le garant. Autrement dit, et c'est là un phénomène absolument important, pas tout à fait unique dans l'histoire sans doute, mais tout de même très singulier au moins à notre époque, l'économie est créatrice du droit public.» (FOUCAULT 2004a, P. 86) Trata-se não de saber que margem de liberdade o Estado deixa ou não aos processos econômicos, mas de saber de que maneira a economia política cria um modo de governamentalização do Estado, isto é, um princípio de regulação interno do Estado. Dado o fato de que Foucault pensa o Estado através de mecanismos de intervenção moldados pela idéia de governamentalidade (FOUCAULT 2004b, P. 92-93), cuja anfibologia remete à idéia de população, podemos observar como este espelhamento entre Estado e economia se institui quando a "contradição biopolítica" é ao mesmo tempo travada, isto é, quando a extensão da economia é assegurada (sécurisée).

Na lição de 21 de fevereiro de 1979, Foucault faz novamente referência às teorias "ordo-neoliberais" partindo da referência de um mercado concorrencial no qual a dinâmica das trocas opera segundo esquemas de auto-regulação garantidos por dispositivos jurídicos e institucionais. Um mercado concorrencial entre empresas produtivas é assegurado por uma intervenção indefinidamente ativa, por onde o 
institucional e o jurídico são tomados como um duplo condicionamento que assegura as condições de realização e atualização desta intervenção constante. Foucault afirma que "entre une économie de concurrence et un Etat, vous voyez bien que le rapport ne peut plus être de délimitation réciproque de domaines différents. Il ne vas pas y avoir le jeu du marche qu'il faut laisser libre, et puis le domaine où l'Etat commencera à intervenir, puisque précisément le marché, ou plutôt la concurrence pure, qui est l'essence même du marché, ne peut apparaître que si elle est produite, et si elle est produite par une gouvernementalité active" (FOUCAULT 2004a,P. 125). Foucault retoma assim a singularidade da "razão neoliberal" por um teorema discursivo e econômico relativo à questão da crise e da sobrevida do capitalismo (FOUCAULT, 2004a, P. 170-173).

Pour reprendre les choses autrement, si vous voulez, pour les ordolibéraux comment se présentaient les choses? Si on fait une analyse un peu grossière et en se disant que leur problème à eux c'était de démontrer que du capitalisme était encore possible, que le capitalisme pouvait sur-vivre à condition qu'on lui invente une nouvelle forme, si on admet que c'est ça l'objectif final des ordolibéraux, on peut dire qu'ils avaient, au fond, deux choses à démontrer. Ils avaient, premièrement, à demontrer que la logique proprement économique du capitalisme, que cette logique du marché concurrentiel était possible et non contradictoire. C'est ce qu'ils ont essayé de faire, ce sont les choses que je vous racontais la dernière fois. Et puis il leur fallait montrer que, cette logique étant en elle-même non contradictoire et par conséquence fiable, il y avait dans les formes concrètes, réelles, historiques du capitalisme, un ensemble de relations juridico-économiques qui étaient telles que l'on pouvait, en inventant un nouveau fonctionnement institutionnel, dépasser des effets - des contradictions, des impasses, des irrationalités -, caractéristiques de la société capitaliste et qui n'étaient pas dus à la logique du capitalisme, mais simplement à une figure précise et particulière de ce complexe économique-juridique. (FOUCAULT 2004a, P. 171) 
Foucault argumenta que o "neoliberalismo" opera pela intervenção do Estado à medida que este desenvolve um mercado concorrencial através de uma estrutura jurídica de maneira que as condições normativas ideais sejam dadas para que a concorrência entre as organizações produtivas possam ser realizadas. Foucault insiste que esta determinação do econômico é acompanhada por uma lógica que substitui o liberalismo clássico pela suplantação do equilíbrio entre um sistema de trocas, cujo princípio de equivalência é oferecido pela moeda e pela não-intervenção do Estado, pela articulação de uma lógica de concorrência e um tipo específico de regulação social. No registro neoliberal, a economia de mercado ultrapassa o liberalismo clássico porque ela substitui o princípio da equivalência da troca entre os indivíduos que, segundo Marx, é na realidade fundada pela equivalência de valor na qual a troca entre o trabalho e o salário é fundada sob a exploração de trabalho não pago, por uma ordem concorrencial na qual os indivíduos são livres de se conduzirem, mas articulados em comum pela concorrência decorrente do princípio de competição entre as empresas.

Foucault discutirá então a este respeito sobre a ideia de uma indexation dos mecanismos de mercado sob a concorrência, de um lado, e, de outro, sobre uma política governamental ativa que governe para o mercado. E para explicá-lo, ele retoma o pensamento de Hayek para caracterizar a natureza destas intervenções incessantes na regulação econômica da sociedade pelo registro do rule of law. Em The Road of Serfdom, Hayek retoma a questão relativa à natureza da intervenção do Estado fazendo passar por lettre morte toda definição do liberalismo como uma simples doutrina do livre mercado independente de qualquer intervenção 
econômica. Hayek permanece uma referência essencial porque ele circunscreve a esfera de intervenção reguladora de um mercado concorrencial por uma denegação de objetivos sociais que poderiam ser instituídos pela sociedade pela mediação de valores coletivos. Sua posição permanece assim articulada em torno da ideia de uma intervenção optimal em favor do uso da competição como melhor forma de coordenar os esforços individuais. Porque, além de permitir aos indivíduos de decidir dos riscos associados às diferentes ocupações em detrimento de outras, as diferentes atividades podem ser ajustadas entre si sem a necessidade da intervenção de uma autoridade, mesmo que uma intervenção se ponha como necessária, quando as condições propícias para um mercado concorrencial não são dadas. Sobre esta intervenção jurídica, a definição de Hayek do Estado de direito não se confunde com a definição do Estado de direito pelo positivismo da lei; trata-se para o autor de La constitution de la liberté de definir o direito como uma regra concernente à definição do dever-ser das leis, ou meta-regra que define:(a) o nível meta-legal que determina a norma do Estado de direito; (b) a legislação entendida na perspectiva da determinação de um conjunto de regras de condutas; (c) o domínio governamental identificado pela promulgação de decretos e regulamentos particulares. (HAYEK 1994, P.256259; DARDOT e LAVAL 2010, P. 166-182.)

Analisando Hayek, Foucault nos demonstra que o rule of Law designa stricto sensu regras abstratas e impessoais independente dos fins particulares perseguidos pelos indivíduos, manifestas no direito privado e penal, mas irredutíveis às regras de direito público entendidas como regras incorporadas no seio de uma organização. Enquanto regras de direito privado, tais regras operam a partir das condutas 
dos sujeitos independente de seus objetivos, o oposto, portanto, da pretensão de inscrever um plano que programa as leis em função de uma regulação social. Trata-se de definir um quadro no interior do qual os agentes econômicos atuam segundo uma lógica individual que serve para edificar as regras jurídicas por meio de um mecanismo de seleção operando no curso de um processo natural. Foucault faz referência no pensamento de Hayek ao fato que uma ordem econômica normativamente determinada é produto de uma ação jurídica no sentido forte do termo.

L'économie est un jeu et l'institution et l'institution juridique qui encadre l'économie doit être pensée comme règle de jeu. Le Rule of law et l'État de droit formalisent l'action du gouvernement comme un prestateur de règles pour un jeu économique dont les seuls partenaires, et dont les seuls agents réels, doivent être les individus, ou disons, si vous voulez, les entreprises. Un jeu d'entreprises réglé à l'intérieur d'un cadre juridico-institutionnel garanti par l'État: c'est cela qui est la forme générale de ce que doit être le cadre institutionnel dans un capitalisme rénové. Règle de jeu économique et non pas contrôle économico-social voulu. C'est cette définition de l'État de droit en matière économique, ou du Rule of law en matière économique, que Hayek caractérise dans une phrase qui, je crois, est très claire. Le plan, dit-il, qui s'oppose justement à l'État de droit ou au Rule of law, 'le plan montre comment les ressources de la société doivent être consciemment dirigées pour atteindre un but déterminé. Le Rule of law au contraire consiste à tracer le cadre le plus rationnel à l'intérieur duquel les individus se livreront à leurs activités conformément à leurs plans personnels.' Ou encore Polanyi, dans Logique de la liberté, écrit: 'La principale fonction d'un système de juridiction, c'est de gouverner l'ordre spontané de la vie économique. Le système de la loi doit développer et renforcer les règles selon lesquelles opère le mécanisme compétitif de la production et de la distribution.' On va donc avoir un système de lois comme règle de jeu, et puis un jeu qui va, par la spontanéité de ses processus économiques, manifester un certain ordre concret. Loi et ordre, law and order: ces deux notions, [sur lesquelles] j'essaierai de revenir la prochaine fois et qui ont eu la fortune que vous savez dans la pensée de droit américaine, ne sont pas simplement des notions slogan pour 
une extrême droit américaine butée et originaire du Midwest. Law and order, ça a originairement un sens très précis, qu'on peut d'ailleurs faire remonter bien au-delà de ce libéralisme dont je vous parle. Law and order, ça veut dire ceci: l'État, la puissance publique n'interviendra jamais dans l'ordre économique que sous la forme de la loi, et c'est à l'intérieur de cette loi, si effectivement la puissance publique se limite à ces interventions légales, que va pouvoir apparaître quelque chose qui est un ordre économique qui, lui, sera à la fois l'effet et le principe de sa propre régulation. (FOUCAULT 2004a, P.178-179)

Intervencionismo jurídico, pois, porque para regular um mundo econômico no qual os sujeitos não se conduzem mais segundo a lógica de um sujeito de troca cujo princípio de equivalência é oferecido pela moeda, nem mais tampouco segundo a lógica de um consumidor ou um produtor de valor de uso, mas essencialmente segundo a lógica de uma empresa que se "comporta" no mundo econômico, um intervencionismo jurídico se impõe em função das insuficiências das regulações provenientes da concorrência do mundo econômico. Como as contradições do capitalismo para os autores ligados ao "ordo-neoliberalismo" não são necessariamente expressão da impossibilidade de sua realização histórica, mas, ao contrário, que o capitalismo é perfeitamente viável enquanto lógica econômica; que as tendências contraditórias do mercado são decorrentes das sociedades capitalistas e de seus efeitos centralizadores correlativos, e não efetivamente da lógica do capital; que as tendências oligopólicas do capitalismo que impedem o desdobramento de uma concorrência perfeita, podem, enfim, serem enquadradas por um intervencionismo que regula as regras do jogo concorrencial entre as empresas; a questão sobre a qual se trata de interrogar, é de que maneira o capitalismo pode se reproduzir, pois a estruturação das trocas econômicas em uma estrutura de produção na qual a tota- 
lidade do sistema é garantida, precisa ser assegurada (sécurisée) para que o travamento da contradição entre Trabalho e Capital se mantenha no interior de uma heteronomia da política (Balibar).

Retomemos, para concluir, a perspectiva histórica de Foucault sobre o neoliberalismo relativamente às posições de Polanyi. Se Polanyi procura reinscrever a economia de trocas em um institucionalismo, aludindo então à questão da recontextualização do mercado econômico no interior de um duplo movimento de separação e de incrustação da economia em instituições não-econômicas, por meio de uma descrição do pensamento de Hayek, Foucault insiste, por outro lado, na seguinte linha de argumentação: a autonomização de um mercado concorrencial auto-produtor de suas próprias normas pela eficácia de ordens econômicas. Com Polanyi, igualmente, Foucault pensa que a elucidação da questão normativa das ordens passa pela consideração dos fatores que determinam a evolução dos códigos imanentes do mercado, porque um mercado auto-regulado é uma figura historicamente situável, isto é, o mercado não é auto-regulado a partir de ordens imanentes à sua realização (CAILlE 2005, P. 188). É sob este ponto que podemos compreender então a idéia de Foucault de que o capitalismo histórico é portador de um campo de possibilidades, porque as diferentes ordens normativas inscritas em um mercado auto-regulado são passíveis de diferentes formas de atualização segundo relações de poder oriundas das esferas jurídicas e institucionais. A idéia de uma ordem concorrencial econômica entre parceiros de um sistema de trocas se contrasta, retomando Polanyi, pela contextualização dos sistemas econômicos. Ora, se Polanyi inscreve esta contextualização sob a ótica do conceito de "proteção soci- 
al" e de "autodefesa da sociedade", Foucault vai além de Polanyi, porque ele esclarece a natureza desta contextualização colocando a economia em referência ao sujeito da produção, isto é, o sujeito de um quadro produtivo como totalidade histórica da produção. A questão de Foucault concernente à história da economia política da racionalidade do poder contemporâneo nos parece essencialmente ligada à compreensão da subjetivação da força de trabalho nas engrenagens da acumulação do capitalismo histórico. Com efeito, a retomada da teoria do capital humano de Becker e Schultz se inscreve, de um lado, na compreensão da questão essencial da subjetivação do trabalho no interior dos mecanismos de valorização. A questão do homo economicus corresponde à questão de um sujeito abstrato produtor de valor econômico. De outro lado, como uma resposta à questão da crise do capitalismo pela produção de uma força de trabalho correlativa aos mecanismos de acumulação. Foucault interroga a relação entre capitalismo e o Rule of Law interrogando a questão da sobrevivência do capitalismo histórico no interior de uma reflexão sobre a produção da vida em um sistema heterônomo de autoprodução.

\section{PONDERAC̣ÕES FINAIS}

Como estamos a argumentar, a posição de Foucault concernente a articulação entre o econômico e o institucional na determinação do conceito de "capitalismo histórico", isto é, a compreensão de Foucault do liberalismo econômico como um "modo de governamentalidade" que estrutura as ações dos agentes econômicos por meio de uma racionalidade econômica específica, é melhor compreendida à luz do conceito de população, porque ele dá conta do modo como 
o capitalismo histórico se torna uma realidade universal. $\mathrm{Na}$ medida em que nós tomamos em conta a questão de Marx sobre o "sujeito abstrato" da produção na compreensão das relações entre economia e política no texto de Foucault, Wallerstein constitui uma referência obrigatória, porque ele resignifica o conceito de manager no interior do capitalismo histórico compreendido, como procura fazê-lo Braudel, enquanto uma totalidade determinada pela medida do tempo e pelo espaço econômico das trocas, no interior do qual o Estado se torna uma infra-estrutura necessária à estruturação assimétrica dos agentes econômicos.

Deste modo, os conceitos foucaldianos de "biopolítica" e "governamentalidade" são compreensíveis quando entendidos à luz do conceito de superpopulação relativa ou arma industrial de reserva. Toda proliferação conceitual e histórica de Foucault sobre o problema da "aceleração econômica" das sociedades modernas e dos fenômenos populacionais decorrentes parece-nos mais compreensíveis quando colocados em diálogo com o conceito de superpopulação relativa em Marx. Por outro lado, a afirmação do estatuto institucional do capitalismo enquanto sistema econômico, isto é, o fato de que não existe capitalismo sem ordem, significa que um elemento de força é introduzido na subsunção do trabalho vivo nos processos de acumulação relativamente a uma população excedentária. Pensar a questão da instituição na determinação da economia, isto é, pensar a relação entre domínio econômico e nãoeconômico, significa pensar a questão do management da força de trabalho no interior dos processos de acumulação. Esta questão é essencial na determinação da significação histórica do neoliberalismo segundo Foucault, porque se trata para o autor de Surveiller et Punir de compreender a 
economia pela ótica de uma neutralização das contradições do capitalismo. $\mathrm{O}$ que Polanyi deixa em suspenso do ponto de vista de uma interrogação sobre a sobrevivência do liberalismo contemporâneo, Foucault o resignifica por uma leitura cujo ponto de partida se encontra na descrição de $\mathrm{O}$ Capital a propósito do problema da sobrevivência do capitalismo histórico.

Abstract: The article seeks to understand the status of Foucault's critiques of neoliberalism from the concept of biopolitics developed before his course $\mathrm{La}$ naissance de la biopolitique. Two theoretical presuppositions are mobilized to understand the passage from the issue of biopower to that of neoliberalism: Marx and the concept of relative surplus population, because Foucault's questions on the concept of biopolitics centers around the concept of population. On the other hand, with Polanyi, we can understand how Foucault imagines the novelty of contemporary neoliberalism within an analysis of the contradiction of liberalism as historic capitalism (F. Braudel). In the end, this article aims to analyze the categories of power in Foucault in the field of political economy.

Keywords: biopolitics; neoliberalism; Marx; capitalism institutional.

\section{REFERÊNCIAS}

BALIBAR, E. Foucault et Marx : l'enjeu du nominalisme. In Michel Foucault philosophe : rencontre internationale. $\mathrm{Pa}$ ris: Seuil, 9, 10, 11 janvier 1988.

BRAUDEL, F. La dynamique du capitalisme. Paris: Champs, 2008.

CAILlÉ Alain. Dé-penser l'économie. Paris: La Découverte, 2005.

CANGUILHEM, G. «La formation du concept de régulation biologique». In: Idéologie et rationalité dans l'histoire des sciences de la vie. Paris: Vrin, 2000.

. «Milieu et Normes de l'homme au travail». In: 
Les Cahiers de Sociologie, Seuil, Vol III, 1947.

CASTEL, Robert. Les métamorphoses de la question social. Paris: Gallimard, 1995.

DARDOT, P. e LAVAL, C. La Nouvelle Raison du monde. Essai sur la société néolibérale. Paris: La Découverte, 2009.

DI RUZZA, R. Le marché, quelques observations théoriques ». In Actuel Marx, Le monde est-il un marché ? Paris: Puf, n 9, 1991.

FOUCAULT, M. « La politique de la santé au XVIIIème siècle». In DE II. Paris: Gallimard, 2001, p. 17.

- Naissance de la biopolitique : Cours au Collège de France. 1798-1979. Paris : Gallimard, 2004a.

. Sécurité, Territoire, Population : Cours au Collège de France. 1977-1978. Paris : Gallimard, 2004b.

HAYEK, F. The Road to Serfdom, American Paper Back, 2007.

JAPPE, A. Crédit à mort - la décomposition du capitalisme et ses critiques. Paris: Lignes, 2011.

JEAN-PIERRE, L. Par-delà la biopolitique. In Critique, « Présence de Foucault ». Paris, Revue générale des publications françaises et étrangères, Mai, 2005, Tome LXI, $\mathrm{n}^{\underline{0}}$ 696, pp. 363-365.

LE BLANC, G. La pensée Foucault. Paris: Ellipses, 2006.

LUKACS, G. Histoire et conscience de classe, trad. K. Alexos e J. Bois, Paris, Ed. Minuit, 1969. 
MARX, Karl. Le Capital - Livre 1. Trad. J. P. Lefebvre.Paris: PUF, 2009.

. Introduction aux Grundrisse, Trad. G. Fondu e J. Quétier, Paris, Ed. Sociales 2014, pp. 31-58.

MICHAUD, Y. Des modes de subjectivation aux techniques de soi: Foucault et les identités de notre temps. In Cités - Philosophie, Politique, Histoire,Michel Foucault: de la guerre des races au biopouvoir. Paris: PUF, 2000, pp. 20-21.

POLANYI, K. L'économie en tant que procès institutionnalisé. In CANGIANI, M e MAUCOURANT, J. Ed. Essais de Karl Polanyi. Paris: Seuil, pp. 58-59. ("The Economy as Instituted Process," in POLANYI, K. e CONRAD, ARENSBERG, M. and W. PEARSON, H. Ed. Trade and Market in the Early Empires: Economies in History and Theory.New York: Glencoe Ill, The Free Press, p. 243-270, 1957.)

. La Grande Transformation: Aux origines politiques et économiques de notre temps. Paris : Gallimard, 1983.

WALLERSTEIN, I. Le capitalisme historique. Paris: Ed. La Découverte, 1985. 